\title{
IGSM-TEM Land use in CAM3.1-CLM3.0: Impacts of Land use and biofuels policy on climate
}

\author{
$\underline{\text { Willow Hallgren }}^{1}$, Adam Schlosser $^{1}$ and Erwan Monier ${ }^{1}$ \\ (with insights from: Andrei Sokolov ${ }^{1}$, David Kicklighter ${ }^{2}$, Jerry Melillo ${ }^{1}$, Yongxia Cai ${ }^{1}$, John Reilly ${ }^{1}$, \\ Angelo Gurgel ${ }^{3}$, Ben Felzer ${ }^{4}$, and Sergey Paltsev ${ }^{1}$ ) \\ ${ }^{1}$ Joint Program on the Science and Policy of Global Change, Massachusetts Institute of Technology (MIT), \\ ${ }^{2}$ The Ecosystems Center, Marine Biological Laboratory (MBL), 7 MBL Street, Woods Hole, MA 02543, USA, \\ ${ }^{3}$ Department of Economics, University of São Paulo, Brazil, ${ }^{4}$ Department of Earth and Environmental \\ Sciences, Lehigh University, 31 Williams Drive, Bethlehem, PA 18015, USA. (Email: hallgren@mit.edu)
}

The impact on climate of future land use and energy policy scenarios is explored using two economicallymodelled land-use frameworks: (i) Pure Cost Conversion Response (PCCR), or 'deforestation', where the price of land constrains agricultural conversion, including growing biofuels, and; (ii) Observed Land Supply Response (OLSR), or 'intensification', where legal, environmental and other constraints encourage more intense use of existing agricultural land (i.e. less forest clearing). These two land-use frameworks were used to explore how the large scale plantation of cellulosic biofuels to meet global energy demand impacts the future climate. The land cover of the Community Atmospheric Model Version 3.0 (CAM3.0) was manipulated to reflect these four different land use and energy scenarios (i.e. PCCR and OLSR with and without biofuels). CAM3.0 was run to equilibrium, under 1990 and 2050 climate conditions, in order to assess the impact these land cover changes have on the atmospheric state. For the 2050 climate conditions, CAM was prescribed with concentrations of radiatively active trace gases (a.k.a. greenhouse gases) that result from a moderate stabilization target by the end of the $21^{\text {st }}$ century.

Overall in the extratropics, the intensification and deforestation scenarios increase the land-surface reflectivity over many areas of the globe, indicating that biofuel cropland is replacing darker land-vegetation types, decreasing absorption of solar radiation, which leads to a cooling effect. These patterns are strongest in the northern hemisphere, and occur to a greater extent in the PCCR scenarios. Moreover, the cooling is strongest when a biofuel policy is implemented. These temperature changes are for the most part overwhelmed by the trace-gas forcing (i.e. anthropogenic warming). However, in some regions, land surface changes in the PCCR case can counteract or notably lessen the warming.

In much of the Amazonian and African tropics, however, the PCCR deforestation leads to a decrease in evaporative fraction, and an increase in sensible heat flux, leading to a warming effects over regions where biofuels have replaced tropical forests. These local, land-use induced changes in surface heat fluxes have non-local impacts on cloudiness and precipitation, the majority of which occur over oceans. The majority of the precipitation results show patterns which counteract those due to trace-gas forcing. We conclude that the implementation of a future energy policy where biofuels play a significant part, as well as the way we price land and the constraints placed on deforestation, both have a statistically significant impact on climate in 2050, and the land use change which led to the largest replacement of forested lands with biofuel cropland had the largest latitudinally-dependent impact on temperatures around the world.

Keywords: $\quad$ land use, land cover, biofuels, modeling, climate change 


\section{INTRODUCTION}

Economic studies estimate that future global energy demands will increase from the about 400 exajoules of world commercial energy consumption at the end of the $20^{\text {th }}$ century $-15 \%$ of which is from non-fossil fuel sources - to 550-1000 exajoules per year in 2050, depending on the availability of resources, and how policies to limit greenhouse gases affect energy demands in the future (Clarke et al., 2007; Melillo et al., 2009a). To meet these future energy demands, biofuels have been proposed as a potential low-carbon energy source that, along with other technologies (nuclear, hydro, wind, solar), will reduce greenhouse gas emissions and provide some mitigation to global warming (Pacala and Socolow, 2004; Farrell et al., 2006).

However, large-scale plantations will likely have a large impact on the Earth's land surface, including the possibility of extensive deforestation. Studies that investigated the local and non-local climate impact of land use change, and also specifically deforestation (e.g., Pitman et al. 2009; Bonan, 2008; Henderson-Sellers et al. 1993) motivate the need for a study that investigates the direct climatic impact of extensive land cover change due to future large scale planting of biofuels. However, the use of biofuels to supply growing energy demands occurs in a complex context of economic factors (such as food prices, land prices, population growth, environmental regulation, etc.), which ideally should be taken into account when projecting where and how much biofuel crops are planted, and which are described in Gurgel, Reilly and Paltsev (2007).

Melillo et al. (2009a) used a computable general equilibrium (CGE) model of the world economy, the MIT Emissions Predictions and Policy Analysis model (EPPA, Paltsev et al., 2005; Gurgel et al., 2007), coupled with a process-based terrestrial biogeochemistry model, the Terrestrial Ecosystem Model (TEM, Melillo et al., 1993; Felzer et al., 2004; Sokolov et al., 2008), to generate global land-use scenarios in which an ambitious cellulosic biofuels program over the 21 st century was implemented to help meet future energy demand. The biofuels scenarios were modeled within an integrated assessment framework with the goal of stabilizing the atmospheric $\mathrm{CO}_{2}$ concentration at 550 ppmv by the end of this century (Paltsev et al., 2008).

This study builds on the analytical framework of Melillo et al. (2009a) and addresses multiple questions of whether the policy of using biofuels to meet future energy needs has a statistically significant impact on a variety of local and non-local measures of climate, and compares this to the case where the biofuels policy is not implemented. We explore whether the economic framework used (and hence the presence or lack of environmental constraints on land use) has a statistically significant impact on future climate; and how much of the total climatic change seen in 2050 is solely due to land cover change, and how much is solely due to radiative forcing.

\section{METHODS}

\subsection{Models used}

Complex interactions of economic land use frameworks, energy policy and climate are modeled via an integrated climate impact assessment framework (Fig. 1 of Sokolov et al., 2005). In Melillo et al. (2009a), the linkages between the ecosystem model and the economic model were enhanced to produce scenarios of land use and cover (e.g. areas of cropland, tropical forests, etc.) that reflect different economic controls and biofuel policy in 2050. Their integrated modeling study used greenhouse gas emissions, as projected by EPPA, to drive a coupled atmospheric and climate module within the MIT Integrated Global System Model version 2.2 (IGSM, Prinn et al., 1999; Sokolov et al., 2005) to simulate the future climate that then drives TEM to simulate changes in crop, pasture, and forest productivity due to changing climate, levels of $\mathrm{CO}_{2}$ and tropospheric ozone. These projected changes in productivity are then fed back to the EPPA model to change yields in the agricultural sectors (Reilly et al., 2007). Changes in yields, together with changing demand for these products, as driven by population and income growth, lead to reallocations of land among uses, and conversions of land among land types (Mellilo et al., 2009a). In order to simulate the impact on global climate, the resulting areas of biofuel production from this coupled economics-earth system model were then fed into the Community Atmospheric Model Version 3.1 (CAM 3.1), which includes a coupled global climate-land model framework. The land-surface model in CAM 3.1 contains a comprehensive biogeophysics model - the Community Land Model Version 3.0 (CLM 3.0, Oleson et al., 2004). CAM3.1 includes a slab ocean model (SOM). Coupled together, this CAM-SOM-CLM framework was employed for our simulations (described below).

\subsection{Data}

The data used in the study consists of 1-year snapshots at 1990 and 2050, of land cover as simulated by the Terrestrial Ecosystem Model (TEM, Melillo et al., 1993; Felzer et al., 2004; Sokolov et al., 2008), coupled to the MIT Emissions Predictions and Policy Analysis model, (EPPA, Paltsev et al., 2005; Gurgel et al., 2007), 
as described in Melillo et al. (2009a). The EPPA model calculates percentage of land use for 16 regions globally, and a statistical downscaling approach has been developed to disaggregate this regional land use information to the $0.5^{\circ} \times 0.5^{\circ}$ grid cell resolution required by TEM (Wang, 2008). This approach used information such as net primary productivity (NPP), climate and some economic variables so land would compete between vegetation types. The decision to grow biofuel crops in a particular grid cell occurs only if a minimum of $5 \%$ of the grid cell already grows crops.

In order to utilize the EPPA-TEM-IGSM land use/cover data we translated the IGSM land cover classification scheme (Schlosser et al., 2007) consisting of 34 land cover types, to the CLM3.0 classification scheme, consisting of 17 plant functional types (PFTs) required by the CLM3.0 input land surface dataset (Hallgren et al., 2011, in preparation). In addition to the land-use information, radiative forcing variables (trace gas, and aerosol concentrations, solar constant, etc.) from a $550 \mathrm{ppm}$ stabilization scenario climate simulation by the IGSM (Melillo et al., 2009a) were used in CAM to simulate the climate in 2050.

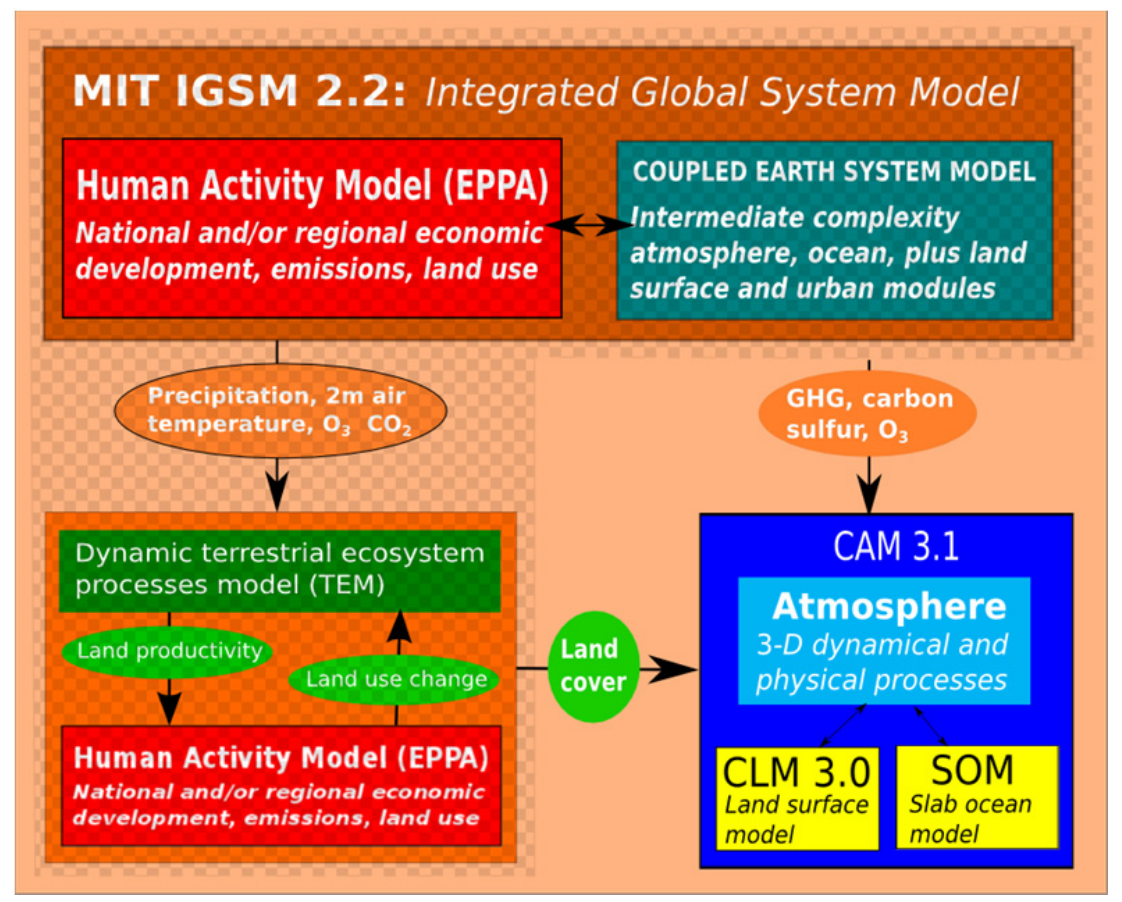

Figure.1. The offline coupling of IGSM 2.2 and CAM3.1-CLM3.0. The checkered area represents the modelling framework of Melillo et al. (2009a).

\subsection{Modeling scenarios}

The two economic frameworks used in this study represent two economically plausible scenarios:

(a) Pure Conversion Cost Response Model (PCCR)

This scenario (or framework) makes all land available for biofuels crops or other managed uses as long as the economic return on the land exceeds the cost of conversion and improvement. This scenario can be thought of as the "deforestation" scenario because it involves large-scale deforestation in support of biofuels production, either directly or indirectly. The direct link between deforestation and biofuels is when forests are cleared to establish biofuels crops (Fargione et al., 2008). Biofuel production is indirectly linked to deforestation when forest clearing occurs to accommodate agricultural crops or pastures which have been displaced by biofuel production (Searchinger et al., 2008).

(b) Observed Land Supply Response Model (OLSR)

This alternative scenario limits access to unmanaged land (e.g., tropical forests), with the limits based on the recent history of regional land conversion rates. This approach results in slower rates of deforestation than would be predicted by cost estimates alone (Gurgel et al., 2007). This scenario can be thought of as the "intensification scenario" because one possible result of limited access to new land is that existing managed lands will be used more intensively, with increased inputs of capital, 
labor and materials such as fertilizers.

Both of these land-use trajectories consider two energy-policies: with and without the inclusion of cellulosic biofuel penetration into the global energy resource portfolio. Energy from cellulosic biofuels plays an important part in the global primary energy supply in 2050 in both scenarios where biofuels are included $141 \mathrm{EJ}$ yr-1 in the deforestation scenario and $128 \mathrm{EJ}$ yr-1 in the intensification scenario. This is enough to meet at least $10 \%$ of the projected global energy requirement in 2050 (Melillo et al., 2009a).

The two economic scenarios result in differing intensities of biofuel production, which is responsible for the different climatic impacts seen. This is due to biofuels replacing other types of vegetation, which have a different influence on climate, to a greater or lesser extent. These areas of biofuel production were derived from a coupled economics-earth system model, and fed (offline) into a coupled climate-land surface model which has a simplified ocean, as described previously.

\subsection{Experimental design}

A total of seven simulations were done using our CAM-SOM-CLM framework, at a spatial resolution of $2^{\circ} \mathrm{x}$ $2.5^{\circ}$. These consisted of (a) a 1990 simulation using the IGSM-TEM derived land cover types which have been reclassified into CLM PFTs. Simulation (b) was conducted with the climate forcing set to 2050 conditions and the land cover set to 1990 conditions, with the aim of comparing this simulation to (a) where both the climate forcing and land surface data are set to 1990, so that the impact of the climate forcing alone (in 2050) can be calculated. Simulations (c) to (f) were conducted with both the climate forcing and the land surface dataset set to 2050 conditions, for each of the four scenarios - two simulations each for the PCCR and OLSR economic frameworks, one with a cellulosic biofuel-based energy policy implemented in 2026 in the original IGSM-TEM data, and one where this energy policy is not implemented.

\section{RESULTS AND DISCUSSION}

The economic framework and energy policy (i.e. biofuels or not) changes the distribution of land cover, including vegetation types, and alters the reflectivity of the land surface. This is because cropland has a higher albedo than the other types of vegetation that it replaces. This changes the radiation budget of the land surface, with more incoming solar radiation reflected, and thus lowering the amount of energy that is available at the surface for partitioning into the latent, sensible and ground (soil) heat fluxes, which is a major determinant of surface climate (Oke, 1987).

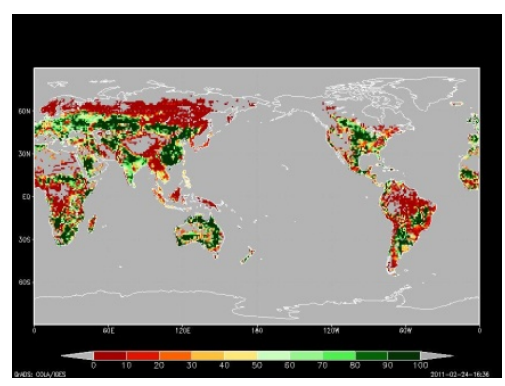

(a) PFT 16 cropland, 1990

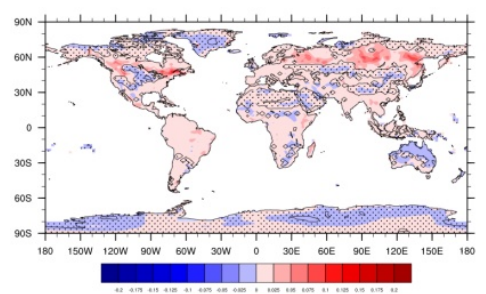

(d) Albedo, LCC Impact (PCCR)

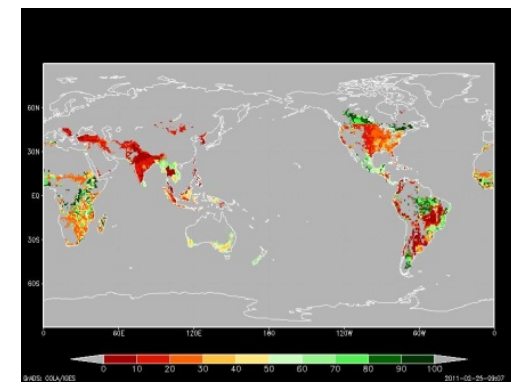

(b) PFT 17 PCCR biofuel, 2050

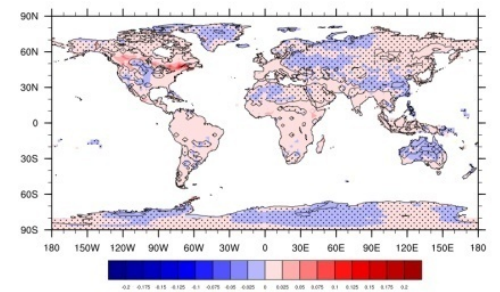

(e) Albedo, PCCR - PCCRNB

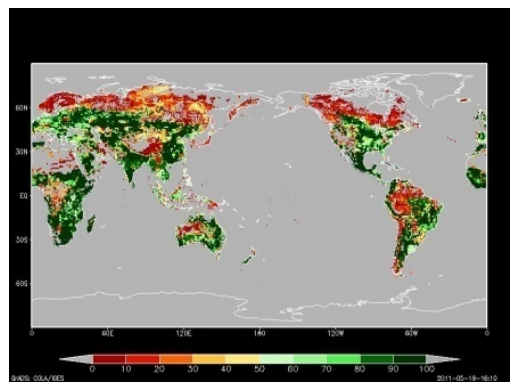

(c) PFT 16+17 PCCR, 2050

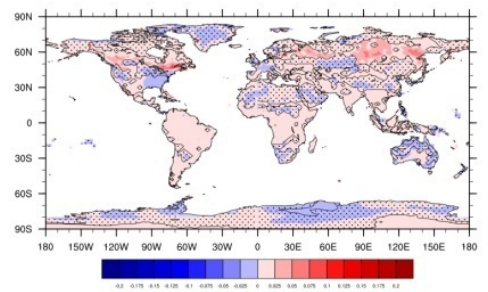

(f) Albedo, PCCR-OLSR

Figure 2. (a) shows the area of 'generic' crop as simulated by IGSM-TEM in 1990, before any economic or biofuel policy has been implemented; (b) shows the global biofuel crop in 2050 that is the result of the biofuel policy; (c) shows the combined generic and biofuel crop area in 2050 i.e. the total extent of global cropland. Fig (d) shows the change in albedo from 1990 to 2050 in the PCCR-with biofuels scenario; (e) shows the difference in albedo between the PCCR and PCCR-no biofuel scenarios in 2050, and (f) shows the 
difference in albedo between the PCCR and OLSR (with biofuels) scenarios in 2050 (areas of red indicate increases in albedo, and blue decreases).

The largest change in albedo occurs in the PCCR scenario, which is due to the greater extent of deforestation in this economic framework controlling land-use, and also because it is the one in which the most biofuel cropland is grown, of all four scenarios, as shown in Figure 2. An assessment of the differences between the 2050 PCCR - OLSR (Fig. 2f) albedo map shows that it is the PCCR scenario -and the greater deforestation it entails - that is the cause of the albedo increases in the high northern latitude in both the USA and Eurasia. This hypothesis is verified by comparing the PCCR-PCCRNB and PCCR-OLSR difference maps for albedo (Fig 2e and 2f); the former shows an increase in albedo only in parts of the North America but not Eurasia, indicating that this change is attributable to the biofuels policy but not the economic framework; the latter shows albedo increases in both North America and Eurasia. The increase in albedo (red) in the northern hemisphere can be accounted for by the increase in 'generic crop land' and biofuels (from OLSR to PCCR).

The primary effect of the increased albedo is to alter the amount of net radiation at the surface, and this will lead to less energy being available to both heat the air (sensible heat flux) and evaporate (latent heat flux). If the evaporative fraction (EF - the ratio of latent heat flux to the sum of latent and sensible heat flux) remains unchanged, this can lower surface temperature, via a concomitant change in the surface sensible heat flux. This is what is seen over much of the northern hemisphere land mass (Fig. 3). The mechanism to explain the decrease in temperatures (from 1990 to 2050) over much of the northern hemisphere is partly the decrease in surface net radiation (Fig. 3a), but there is an increase in EF over much of North America and western Eurasia, as seen in Figure $3 \mathrm{~b}$ which compounds this decrease in surface radiation and lowers temperatures further. However, if the evaporative fraction decreases, there can be still be an absolute increase in sensible heat flux and surface temperature, even with a decrease in surface net radiation, and this occurs in the Amazon (Figs. 3c and 3d).

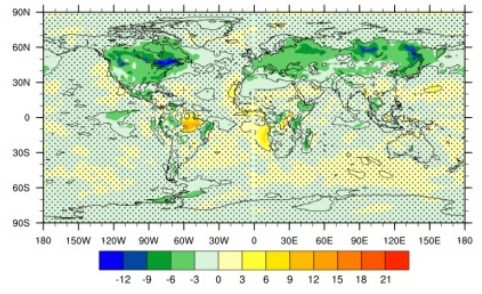

(a) Surface net radiation

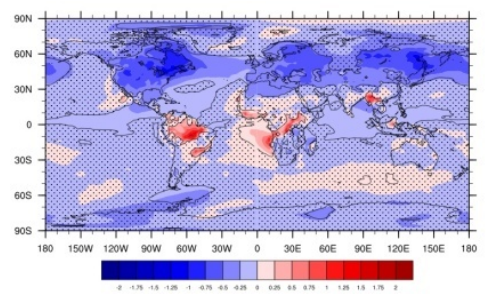

(d) Surface temperature (LCC only)

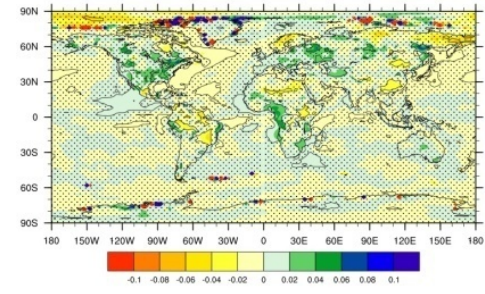

(b) Evaporative fraction

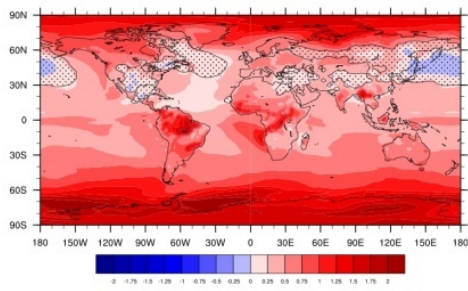

(e) Surface temperature $(\mathrm{LCC}+\mathrm{AGW})$

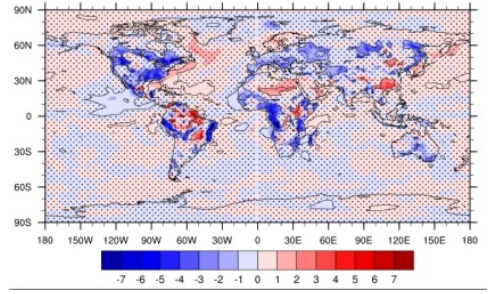

(c) Sensible heat flux

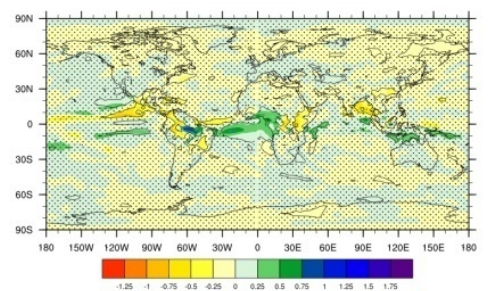

(f) Total precipitation

Figure 3. Results for PCCR scenario, isolating the changes from 1990-2050 due just to land cover change (PCCR framework plus biofuels scenario) except where specified; (a) surface net radiation, (b) evaporative fraction, (c) surface sensible heat, (d) surface temperature, (e) surface temperature in 2050 due to both LCC and anthropogenic global warming, (f) total precipitation.

The difference between the response to deforestation in the tropics (i.e. increase in sensible heat flux and temperature) compared to the extratropics (decrease in sensible heat flux and temperature) occurs because tropical forests maintain high rates of evapotranspiration, which offsets the surface warming from the low albedo of forests. If the forest is cut down and replaced by crop or pasture, then the evaporative fraction can change in response to ecophysiological changes of the new land cover. For example, the replacement of most vegetation types with crops acts to decrease LAI and rooting depth, decreasing the capacity to transpire moisture from the soil, lowering canopy evaporation, and reducing access to deeper soil water. Also a lower canopy height will reduce the turbulent transfer of heat to the atmosphere, (e.g. Pitman et al., 2009) all of 
which leads to less evaporative cooling. Both modeling and flux tower studies confirm that in the Brazilian Amazon, forests have lower albedo compared with pasture, greater net radiation, and greater evapotranspiration, particularly during the dry season. The same processes have been found to occur in the tropical forests of Africa and Asia (Bonan, 2008).

Changes in circulation patterns in these simulations have also produced non-local precipitation responses. Generally speaking, the greater rate of deforestation and replacement by biofuels in the PCCR case has the most impact on precipitation. There are three main non-local precipitation responses which are the result of land cover change only (Fig. 3f; (a) the Gulf of Guinea shows a nearly $50 \%$ increase (i.e. $0.75 \mathrm{~mm} / \mathrm{d}$ ) in convective precipitation from 1990 to 2050, this is also seen to a lesser extent in the OLSR scenario; (b) the ocean west of meso-America, in an east-west area extending out into the middle Pacific, shows a decrease of up to $1 \mathrm{~mm} / \mathrm{d}$, and (c) the Bay of Bengal shows a decrease in precipitation of up to $0.75 \mathrm{~mm} / \mathrm{d}$. More local precipitation impacts include increases and decreases over northern South America, and an increase to the north and northeast of Australia. A preliminary analysis indicates that the economic framework does not cause this rainfall result as the differences between the scenarios with and without biofuels illustrate that the biofuels policy is largely responsible for this rainfall pattern. A regional circulation analysis will be employed in an upcoming paper to comprehensively analyze these precipitation results.

\section{CONCLUSIONS}

Our results indicate that land use pricing has less effect on surface temperature and precipitation than a biofuels policy, even when these biofuels grown will only meet $10 \%$ of future energy needs, but that it is the PCCR framework which has a more widespread impact, particularly on the surface albedo, net radiation, the energy budget and cloudiness. This is likely because albedo changes due to just the difference between the economic scenarios are more extensive - i.e. there are large areas of albedo increase in the PCCR framework (with biofuels) that the OLSR framework (with biofuels) lacks. These albedo changes in Eurasia cause concomitant decreases in surface radiation, however EF is impacted more by biofuels everywhere except Eurasia, compared to the no-biofuels scenarios. It is the impact of the biofuel policy on the EF that leads to more severe changes in the tropical regions, particularly in surface radiation, and also in equatorial African latent heat flux, sensible heat flux and total cloudiness, and as preliminary results suggest, non-local impacts on precipitation. These results suggest that although the impacts of the greater deforestation from the PCCR framework occur more widely, it is the disruption to the tropical hydrology in Africa by the biofuel policy which causes more severe impacts on this region.

It is clear that the way we price land and our choices of energy policy feed directly into sustainability issues in that future climate is significantly impacted by land use and energy policies which either preserve forests or destroy and replace them with biofuels cropland. Generally speaking, the land use change that led to the largest replacement of forested lands with biofuel cropland had the largest impact on temperatures around the world. However the large scale deforestation has a potential ramification in terms of a loss of carbon sink. This is a potentially larger concern in the high northern latitudes where the loss of forest can also effect permafrost and soil carbon - potentially an additional positive feedback to warming, as well as a loss of biodiversity.

\section{ACKNOWLEDGMENTS}

This research is funded by a grant from the US Department of Energy. The authors gratefully acknowledge the financial support for this work provided by the MIT Joint Program on the Science and Policy of Global Change through a number of Federal agencies and industrial sponsors (for the complete list see http://globalchange.mit.edu/sponsors/current.html).

\section{REFERENCES}

Bonan, G.B. (2008). Forests and Climate Change: Forcings, Feedbacks, and the Climate Benefits of Forests, Science, 320:1444-1449.

Clarke, L. E., J. A. Edmonds, H. D. Jacoby, H. M. Pitcher, J. M. Reilly and R. G. Richels (2007). Scenarios of Greenhouse Gas Emissions and Atmospheric Concentrations (Sub-report 2.1A of Synthesis and Assessment Product 2.1 by the U.S. Climate Change Science Program and the Subcommittee on Global Change Research, Dept. of Energy, Office of Biological \& Environmental Research: Washington, DC, USA.

Farrell, A. E., R. J. Plevin, B. T. Turner, A. D. Jones, M. O’Hare and D. M. Kammen (2006). Ethanol can contribute to energy and environmental goals. Science, 311: 506-508. 
Fargione, J., J. Hill, D. Tilman, S. Polasky and P. Hawthorne (2008). Land clearing and the biofuel carbon debt. Science, 319: 1235-1238 (doi:10.1126/science.1152747).

Felzer, B., D. Kicklighter, J. Melillo, C. Wang, Q. Zhuang and R. Prinn (2004). Effects of ozone on net primary production and carbon sequestration in the conterminous United States using a biogeochemistry model. Tellus, 56B: 230-248.

Gurgel, A., J. Reilly and S. Paltsev (2007). Potential land use implications of a global biofuels industry. J. Agric. Food Industrial Org., 5(2): 1-34.

Hallgren WS, Schlosser CA and Monier W (2011). IGSM-TEM Land use in CAM3.1-CLM3.0: Impacts of Land use and biofuels policy on climate. In preparation.

Henderson-Sellers, A., R. E. Dickinson, T. B. Durbidge, P. J. Kennedy, K. McGuffie, and A. J. Pitman (1993). Tropical deforestation: Modelling local to regional-scale climate change, J. Geophys. Res., 98, 7289 - 7315, doi:10.1029/92JD02830.

Melillo JM, Gurgel AC, Kicklighter DW, Reilly JM, Cronin TW, Felzer BS, Paltsev S, Schlosser CA, Sokolov AP and Wang X (2009a). Unintended Environmental Consequences of a Global Biofuels Program, Report 168, January, 34 p. (http://web.mit.edu/globalchange/www/MITJPSPGC_Rpt168.pdf).

Melillo JM, Reilly JM, Kicklighter DW, Gurgel AC, Cronin TW, Paltsev S, Felzer BS, Wang X, Sokolov AP, Schlosser CA (2009b). Indirect Emissions from Biofuels: How Important?, Science, 326: $1397-$ 1399.

Melillo, J. M., A. D. McGuire, D. W. Kicklighter, B. Moore, C. J. Vorosmarty and A. L. Schloss (1993). Global climate change and terrestrial net primary production. Nature, 363: 234-240.

Oke TR (1987). Boundary layer climates (Second edition). Methuen. Pp. $435+$ xvi.

Oleson, K. W., Dai Y., Bonan G., Bosilovich M., Dickinson R., Dirmeyer P., Hoffman F., Houser P., Levis S., Niu G.-Y., Thornton, P., Vertenstein M., Yang Z.-L., Zeng X. (2004). Technical Description of the Community Land Model (CLM), NCAR Technical Note, NCAR/TN-461+STR.

Pacala, S., and R. Socolow (2004). Stabilization wedges: solving the climate problem for the next 50 years with current technologies. Science, 305: 968-972.

Prinn, R., H. Jacoby, A. Sokolov, C. Wang, X. Xiao, Z. Yang, R. Eckhaus, P. Stone, D. Ellerman, J. Melillo, J. Fitzmaurice, D. Kicklighter, G. Holian and Y. Liu (1999). Integrated global system model for climate policy assessment: Feedbacks and sensitivity studies. Climatic Change, 41: 469-546.

Pitman, A.J., de Noblet-Ducoudre, N., Cruz, F.T., Davin, E.L., Bonan, G.B., Brovkin, V., Claussen, M., Delire, C., Ganzeveld, L., Gayler, V., van den Hurk, B.J.J.M., Lawrence, P.J., van der Molen, M.K., Muller, C., Reick, C.H., Seneviratne, S.I., Strengers, B.J., and Voldoire, A. (2009). Uncertainties in climate responses to past land cover change: First results from the LUCID intercomparison study, Geophysical Research Letters, 36, L14814, doi:10.1029/2009GL039076

Paltsev, S., J. Reilly, H. Jacoby, R. Eckaus, J. McFarland and M. Babiker (2005). The MIT Emissions Prediction and Policy Analysis (EPPA) Model: Version 4 MIT JPSPGC, Report 125, August, 72 p. (http://web.mit.edu/globalchange/www/MITJPSPGC_Rpt125.pdf).

Paltsev, S., J. Reilly, H. Jacoby, A. Gurgel, G. Metcalf, A. Sokolov and J. Holak, (2008). Assessment of US Cap-and-Trade Proposals. Climate Policy, 8(4): 395-420; see also MIT JPSPGC, Report 146, April, 95 p.

Reilly, J., S. Paltsev, B. Felzer, X. Wang, D. Kicklighter, J. Melillo, R. Prinn, M. Sarofim, A. Sokolov and C. Wang, (2007). Global economic effects of changes in crops, pasture and forests due to changing climate, carbon dioxide and ozone. Energy Policy, 35: 5370-5383.

Searchinger, T., R. Heimlich, R.A. Houghton, F. Dong, A. Elobeid, J. Fabiosa, S. Tokgoz, D. Hayes and T.$\mathrm{H}$. Yu (2008). Use of U. S. croplands for biofuels increases greenhouse gases through emissions from land-use change. Science, 319: 1238-1240, doi: 10.1126/science.1151861.

Schlosser, C.A., D. Kicklighter and A. Sokolov (2007). A Global Land System Framework for Integrated Climate-Change Assessments, Joint Program Report Series \#147, 60 pages.

Sokolov, A.P., C.A. Schlosser, S. Dutkiewicz, S. Paltsev, D.W. Kicklighter, H.D. Jacoby, R.G. Prinn, C.E. Forest, J.M. Reilly, C. Wang, B. Felzer, M.C. Sarofim, J. Scott, P.H. Stone, J.M. Melillo and J. Cohen, (2005). The MIT Integrated Global System Model (IGSM) Version 2: Model Description and Baseline Evaluation, Joint Program Report Series \#124, 40 pages.

Sokolov, A. P., D. W. Kicklighter, J. M. Melillo, B. S. Felzer, C. A. Schlosser and T. W. Cronin (2008). Consequences of considering carbon-nitrogen interactions on the feedbacks between climate and the terrestrial carbon cycle. Journal of Climate, 21: 3776-3796 (doi: 10.1175/2008JCLI2038.1).

Wang, X. (2008). Impacts of Greenhouse Gas Mitigation Policies on Agricultural Land. PhD thesis, Massachusetts Institute of Technology. 162pp. 